\title{
UM CASO DE TRANSLOCAÇÃO EM UM HÍBRIDO ENTRE ZEA MAYS L. E Z. MEXICANA (SCHRAD.) KUNTZE (1)
}

\author{
NEIVA. IZABEL PIEROZZI $\left({ }^{2,3}\right)$ e NEUSA DINIZ DA CRUZ $\left({ }^{2}\right)$
}

\begin{abstract}
RESUMO
Foi constatada, citologicamente, a presença de uma translocaçāo heterozigota envolvendo dois cromossomos não-homólogos em um híbrido entre Zea mays L. e Z. mexicana (Schrad.) Kuntze. As análises citológicas foram feitas na microsporogênese das plantas híbridas, onde se observou a característica configuração em cruz que os cromossomos translocados assumem na fase de paquíteno, bem como as configuraçðes em cadeia ou anel na diacinese e anel torcido na metáfase I. A contagem dos grãos de pólen indicou $44,0 \% \pm 1,2$ de esterilidade, que foi atribuída diretamente à translocação e não à hibridação. Devido ao mau espalhamento dos cromossomos na fase de paquíteno, não se puderam identificar os cromossomos envolvidos na translocação, estimando-se, porém, que estejam entre os três cromossomos maiores đo genoma (cromossomos 1,2 e 3 ).
\end{abstract}

Termos de indexação: translocaçāo heterozigota, Zea mays, $Z$, mexicana, hîbrido interespecífico, semi-esterilidade.

\section{INTRODUÇÃO}

É comum a ocorrência de híbridos interespecíficos envolvendo Zea mays L. (milho) e Zea mexicana (Schrad.) Kuntze (= Euchlaena mexicana

( $\left.{ }^{1}\right)$ Trabalho apresentado na XXIX Reuniā̃o da SBPC, São Paulo, 1977. Recebido para publicação em 13 de junho de 1984.

(2) Seção de Citologia, Instituto Agronômico (IAC), Caixa Postal 28, 13100 Campinas (SP).

$\left({ }^{3}\right)$ Com bolsa de suplementação do CNPq. 
Schrad.) (teosinto), sendo que os mesmos são robustos e altamente férteis, como observado por WILKES $(1967,1972,1977,1979)$.

Estudos citogenéticos, conduzidos por pesquisadores como LONGLEY (1941), REEVES \& MANGELSDORF (1942) e WILKES (1967, 1972), mostraram a grande homologia entre os cromossomos de ambas as espécies.

Entre as diversas raças de teosinto que ocorrem naturalmente ao longo das regiões mexicanas, está a Chalco. WILKES (1967), analisando o comportamento meiótico de híbridos entre algumas raças de teosinto com o milho, observou que o processo era praticamente normal e a taxa de fertilidade do grão de pólen desses híbridos era alta, notadamente naqueles com a raça Chalco ( $98 \%$ de pólen fértil). Observou, também, a ocorrência de uma alça ("loop") pequena nos segmentos finais dos cromossomos 3, 8 e 9, mas que não era constante em todas as células analisadas. Segundo o autor, essas alças provavelmente seriam causadas por pequenos rearranjos cromossômicos ou pela ausência de homologia na extensão não-pareada desses cromossomos.

A ocorrência de translocações recíprocas em linhagens híbridas de milho com o teosinto foi documentada por BEADLE (1932) e ARNASON (1936) entre outros. Embora as translocações, por via de regra, ocasionem um gradiente de esterilidade, são consideradas importantes para o melhoramento genético, pois se constituem, segundo ANDERSON (1956), num instrumento auxiliar na in trodução de genes de importância econômica dentro de linhas selecionadas mais ou menos homozigotas e que constituem a base do milho híbrido, ou mesmo na localização de genes ou grupos de ligação (BURNHAM, 1956).

Foi utilizado um híbrido interespecífico entre um sintético da raça Tuxpeño de milho e o teosinto 'Chalco' cedido pelo Prof. Dr. William J. Silva, da UNICAMP. Uma análise citológica da microsporogênese dessas plantas revelou a ocorrência de uma translocação recíproca envolvendo dois cromossomos, evidenciada pela presença da característica configuração em cruz que os cromossomos translocados assumem na fase de paquíteno, bem como as configuraçðes em cadeia e em anel em diacinese, e o anel torcido em metáfase I, além da semi-esterilidade do pólen advinda de tal mutação cromossomica.

\section{MATERIAL E MÉTODO}

$O$ híbrido $F_{1}$ analisado foi obtido do cruzamento do sintético designado por CEC $1227(2 \mathrm{n}=20)$ com o teosinto $Z$. mexicana, raça Chalco $(2 n=20)$, utilizado como doador de pólen. Esse cultivar sintético foi obtido pela recombinação de representantes da raça Tuxpeño que apresenta- 
ram àlta capacidade de recombinação com o testador, Ip 1227, um híbrido simples da raça Cateto. Trata-se, portanto, de um material altamente heterogêneo e com poucas chances de apresentar translocação $\left({ }^{4}\right)$.

As inflorescências primeiramente fixadas em Carnoy 3:1 (solução constituída de três partes de álcool etílico absoluto e de uma parte de ácido acético glacial), foram armazenadas em congelador a $-20^{\circ} \mathrm{C}$ até o preparo das lâminas. Uma parte do material foi conservada no próprio fixador e outra, transferida para solução de álcool etílico a $70 \%$

As lâminas foram preparadas utilizando-se os botðes florais segundo o método usual (MEDINA \& CONAGIN, 1964), isto é, por esmagamento de anteras, ora com carmim acético, ora com carmim propionico, sendo que este último foi empregado para a visualização dos cromossomos em paquíteno.

As células-mães de pólen foram analisadas na meiose, principalmente nas fases de paquíteno, diacinese, metáfase I e tétrades de micrósporos, sendo que em diacinese e metáfase I considerou-se o número e calculou-se a porcentagem de células que mostraram associaçðes de cromossomos decorrentes da translocação.

A viabilidade do pólen (pólen com protoplasma) foi calculada pela contagem de grãos coloridos pela ação do carmim acético nas preparações citológicas.

\section{RESULTADOS}

Os resultados obtidos da análise da microsporogênese do híbrido estão sumarizados no quadro 1 . Pode-se observar que, em diacinese, a porcentagem de células com os cromossomos formando tetravalentes na configuração em cadeia (Figura 2B) foi maior do que na configuraçăo em anel (Figura 2C). Além das células com $10_{\text {II }}$ normais (Figura $2 \mathrm{C}$ ) e daquelas que formaram cadeia ou anel, notou-se a ocorrência de cromossomos "sticky" (aderidos) entre alguns bivalentes.

Em metáfase I, observou-se que o anel torcido, em forma de oito, característico dos cromossomos translocados, ocorria em $22,8 \% \pm 0,02$ das células analisadas (Figura 2E). Embora não esteja registrado no quadro 1, a média de quiasmas por bivalente foi 2 , estimando-se em 3 a 4 o número de quiasmas ocorrido no tetravalente (configuração assumida pelos dois cromossomos translocados).

(4) William José da Silva. Comunicação pessoal. 
QUADRO 1 - Comportamento dos cromossomos em um híbrido entre Zea mays L. e Z. mexicana (Schrad.) Kuntze

\begin{tabular}{|c|c|c|c|c|c|c|c|c|c|}
\hline \multirow{3}{*}{ Fase } & \multicolumn{9}{|c|}{ Pareamento e configuração dos cromossomos } \\
\hline & \multirow[b]{2}{*}{ no } & $10_{\text {II }}$ & \multicolumn{3}{|c|}{$\begin{array}{l}10_{\text {II }} \text { e aglutinaçăo } \\
\text { nos cromossomos }\end{array}$} & \multicolumn{2}{|l|}{$\begin{array}{c}8_{I I}+1_{I V} \\
\text { cadeia }\end{array}$} & $\begin{array}{c}8_{\text {II }}+1_{\text {IV }} \\
\text { anel }\end{array}$ & \multirow{2}{*}{$\begin{array}{c}\text { Total de } \\
\text { células }\end{array}$} \\
\hline & & $\%$ & nọ & $\%$ & nọ & $\%$ & nọ & $\%$ & \\
\hline Diacinese & 868 & $88,3 \pm 0,01$ & 17 & $1,6 \pm 0,004$ & 98 & $8,9 \pm 0,01$ & 13 & $1,2 \pm 0,004$ & 1.096 \\
\hline Metáfase I & 292 & $77,2 \pm 0,02$ & & & 86 & $22,8 \pm 0,02$ & & & 378 \\
\hline
\end{tabular}

Em nenhuma célula foi verificada a ocorrência de pontes cromossômicas, seja em anáfase I, seja em anáfase II. Neste aspecto, a disjunção dos cromossomos translocados foi, aparentemente, normal.

O exame de células na fase de tétrades de micrósporos não indicou anomalias acentuadas de número ou de conteúdo citoplasmático dos mesmos, sendo, portanto, regular a sua formação. A análise de 1.792 grãos de pólen revelou a ocorrência de 792 grãos inviáveis (estéreis), correspondendo a 44,0\% $\pm 1,2$, e 1.000 grãos viáveis (férteis) correspondendo a $56,0 \% \pm 1,2$.

A despeito do número de lâminas preparadas, não se conseguiu identificar, na fase de paquíteno, os dois bivalentes envolvidos na translocação, em parte devido ao mau espalhamento cromossomico, característico nesse cultivar (Figura 2A). De acordo, porém, com a quantidade de cromatina presente, estima-se estar entre os três primeiros. Além disso, pela análise em paquíteno parece não se tratar do cromossomo nucleolar 6 (Figura 1) nem dos cromossomos 4 e 5 , devido às peculiaridades mais evidentes desses très últimos.

Nenhum teste citológico pôde ser feito para evidenciar a presença da translocação nos progenitores.

\section{DISCUSSÃO}

As translocações cromossômicas podem ocorrer espontaneamente na natureza ou ser induzidas por agentes físicos ou químicos. São reconhecidas pela semi-esterilidade que causam quando em heterozigose e pela configuração em cruz que os cromossomos assumem na fase de paquíteno (BURNHAM, 1956) (Figura 2A). Este grau de esterilidade é variável, em conseqüência: (1) da extensão dos segmentos cromossômicos translocados; (2) 


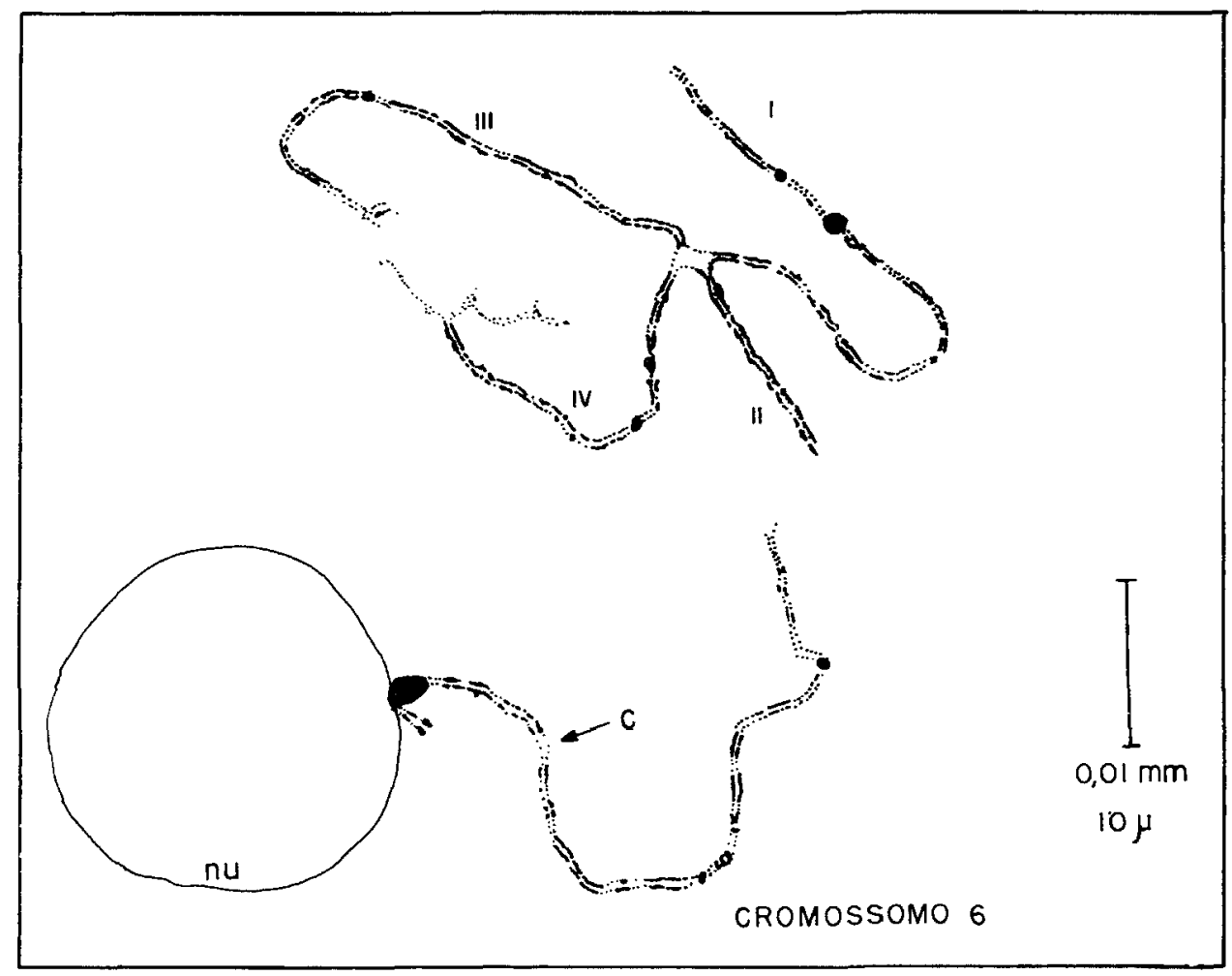

FIGURA 1 - Esquema de uma célula-mãe de pólen em paquíteno onde foi destacado o cromossomo nucleolar 6, e, separadamente, os dois bivalentes com segmentos translocados pareados na configuração de cruz. Os algarismos I, II, III e IV referem-se aos braços da cruz; nu = nucléolo; $\mathrm{c}=$ centrômero.

do tipo de configuração mais freqüente na diacinese; (3) do tipo de segregação que ocorre na anáfase $\mathrm{I}$; e, (4) do número e da posição dos quiasmas nos cromossomos translocados (BURNHAM, 1956, 1962).

BRINKS (1927), por exemplo, encontrou cerca de $50 \%$ de esterilidade para uma linhagem de milho identificada, mais tarde, como portadora de uma translocação envolvendo os cromossomos 1 e 2 . Valores menores ou maiores do que este foram encontrados em milho por BEADLE (1932), ARNASON (1936) e BURNHAM (1950b), sendo que esta variação seria não só decorrente dos cromossomos que estariam envolvidos na translocação como da extensão dos segmentos translocados. BURNHAM (1950a, b, 1962) observou que havia uma provável relação entre a ocorrência de permuta intersticial e a configuração assumida pelos cromossomos translocados na metáfase I, com o tipo de segregação cromossômica que ocorria na anáfase I 

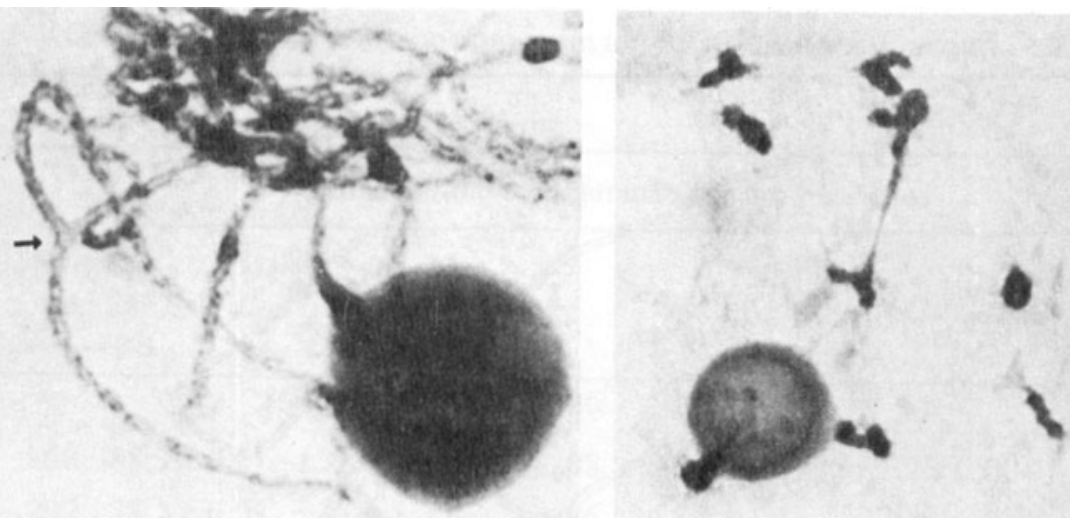

A

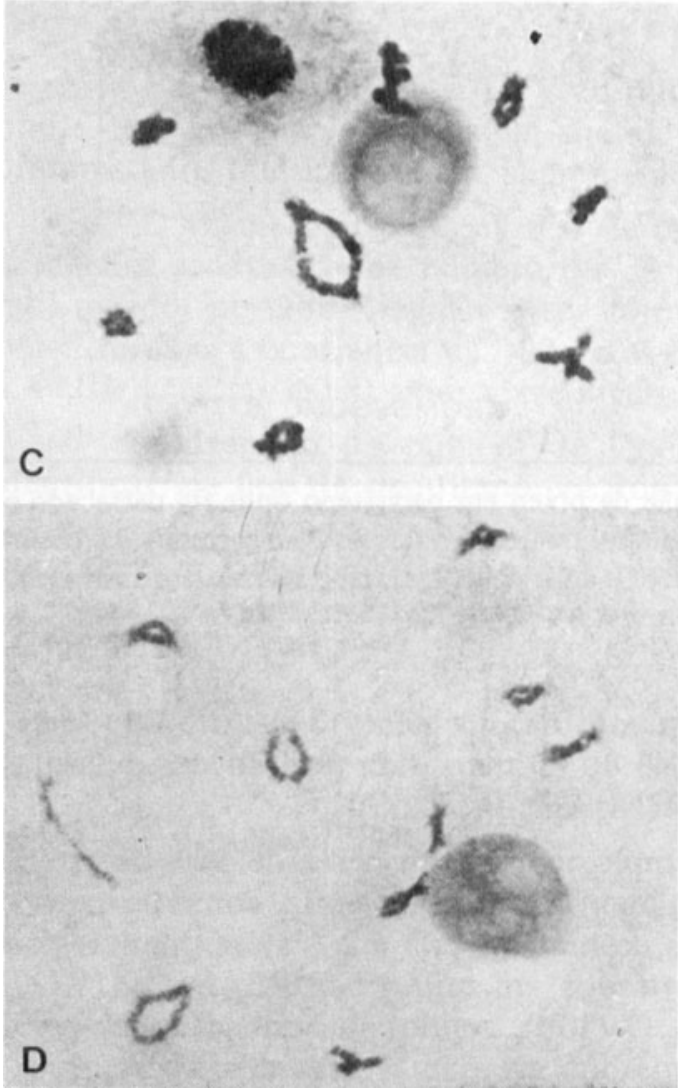

B

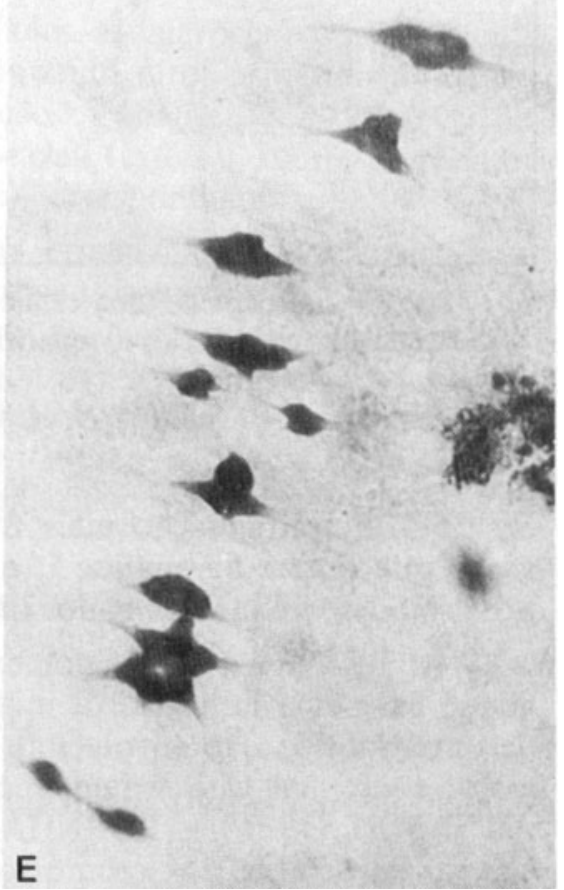

FIGURA 2 - Microsporogênese do hrbrido $\mathrm{F}_{1}$ de Zea mays $\mathrm{x}$ Z. mexicana. A: paquíteno com os cromossomos translocados na configuração de cruz. X 1920; B a D: diacinese. B: $8_{\text {II }}+$ IV em cadeia. X 768; C: $8_{\text {II }}+1$ anel de 4. X 768; D: $10_{\text {II }}$ normais. X 614; E: metáfase com $8_{\mathbf{I I}}+1$ anel de 4 . X 1200 . 
Na planta, a ocorrência de associação dos cromossomos translocados foi acentuadamente diferente em diacinese $(10,1 \% \pm 0,01=$ cadeia + anel) e em metáfase $I(22,8 \% \pm 0,02)$. A diferença nos valores obtidos nessas duas fases meióticas provavelmente se deva a: (1) uma redução no número de quiasmas devida à homologia incompleta dos cromossomos translocados (SYBENGA, 1975); (2) a uma reduzida extensão dos segmentos translocados que promoveria a formação só de alguns bivalentes, e (3) a erros na interpretação e posterior inclusão de cromossomos aderidos como sendo os translocados A curta extensão dos segmentos translocados estaria, de acordo com BURNHAM (1962), relacionada com uma freqüencia maior da configuração do tipo cadeia $(8,9 \% \pm 0,01)$ e também da ocorrência de bivalentes $(88,3 \% \pm 0,01)$ como suposto acima no item (2).

A terminalização precoce de todos os quiasmas dos cromossomos translocados em diacinese não foi suposta, mesmo porque MAGUIRE (1979) fez observaçðes contrárias a esta em milho, inclusive em linhagens com uma translocaçăo que envolvia segmentos de extensão considerável.

A esterilidade observada no híbrido foi de $44,0 \% \pm 1,2$. Esse resultado pode ser explicado pelo: (1) comprimento dos cromossomos envolvidos na translocação, os quais provavelmente estariam entre os três primeiros fato que permitiria flexibilidade suficiente ao anel para assumir a configuração de anel torcido ou de oito na placa metafásica, favorecendo determinados tipos de segregação; e, (2) número e localização dos quiasmas dentro do complexo translocado, que alteraria o tipo de segregação e a fertilidade da planta; este último item, porém, só pode ser analisado por meio de cruzamentos associados a genes marcadores, como efetuado por BEADLE (1932).

A fertilidade esperada seria ao redor de $50 \%$. Esse pequeno aumento $(56 \% \pm 1,2)$ observado poderia ser explicado com base nos argumentos de BURNHAM $(1950,1962)$, onde os tipos de segregação alternada e adjacente-1 seriam favorecidos, independente da configuração de cadeia ou anel dos cromossomos translocados, devido à presença de permutas intersticiais. Juntamente com essa explicação, estaria o comprimento do segmento translocado, que favoreceria um aumento de fertilidade.

Foi observado em paquíteno que os "knobs" do híbrido parecem estar em homozigose. Segundo WILKES (1967), a raça Chalco de teosinto representa um tipo mazóide, pois apresenta muitas semelhanças tanto morfológicas quanto fisiológicas com o milho, e o híbrido, quando ocorre em faixas cultivadas, é difícil de ser distinguido dos cultivares de milho comercial, exceto na época do florescimento. 


\title{
5. CONCLUSÕES
}

1) A esterilidade observada neste hibrido entre $Z$. mays e $Z$. mexicana provavelmente esteja associada à presença de uma translocação heterozigota envolvendo dois cromossomos não-homólogos, e não à baixa homologia dos cromossomos das espécies paternas envolvidas.

2) A porcentagem maior de células em diacinese com os cromossomos translocados na forma de cadeia ou em pares deve ser conseqüência do pequeno comprimento dos segmentos envolvidos na translocação.

3) A diferença nos valores obtidos dos cromossomos translocados associados na forma de tetravalentes das células em diacinese e em metáfase I pode ser explicada (a) pela reduçăo do número de quiasmas entre os segmentos translocados; (b) pelo tamanho relativo dos segmentos translocados, e (c) pela inclusão, devida a erros de interpretação, de cromorsomos aderidos como sendo os translocados.

4) As configuraçðes assumidas pelos cromossomos translocados, no híbrido, juntamente com a ocorrència e a posição de quiasmas, provavelmente favoreça as segregaçós do tipo alternada e adjacente-1.

5) Em decorrência do último item e do comprimento dos cromossomos translocados, a fertilidade pôde ser aumentada.

\section{SUMMARY}

\section{CHROMOSOMAL TRANSLOCATION IN A HYBRID BETWEEN ZEA MAYS L.} AND Z. MEXICANA (SCHRAD.) KUNTZE

\begin{abstract}
A heterozygous translocation involving two non homologous chromosomes was observed in a hybrid between Zea mays L. and Z. mexicana (Schrad.) Kuntze. The cytological observations were made at the microspore phase. A cross-shaped synaptic figure formed by the translocated chromosomes was shown at pachytene as well as the chain configurations at diakinesis and ring shaped formations at metaphase I. Pollen sterility was $44.0 \% \pm 1.2$ and it was probably due to the presence of the translocation rather than to the interspecific hybridization itself. Because of poor pachytene spreading, chromosomes involved in the translocation could not be identified. However, they appear to belong to the group of the large chromosomes (1, 2 or 3).
\end{abstract}

Index terms: heterozygous translocation; Zea mays, $Z$ mexicana, interspecific hybrid, semi-sterility.

\section{AGRADECIMENTOS}

As autoras agradecem ao Prof. Dr. William José da Silva, do Departamento de Genética da UNICAMP, ter cedido gentilmente o material para estudos, bem como às biólogas Maria Regina $\mathrm{C}$. Wutke e Mônica C. Penteado a colaboração na parte da coleta de material. 


\section{REFERÊNCIAS BIBLIOGRÁFICAS}

ANDERSON, E.G. The application of chromosomal techniques to maize improvement. In: BROOKHAVEN SYMPOSIA IN BIOLOGY: GENETICS IN PLANT BREEDING 9., New York, 1956. p.23-36.

ARNASON, T.J. Cytogenetics of hybrids between Zea mays and Euchlaena mexicana. Genetics, 21:40-60, 1936.

BEADLE, G.W. The relation of crossing over to chromosome association in Zea-Euchlaena hybrids. Genetics, 17:401-501, 1932.

BRINKS, R.A. The occurrence of semi-sterility in maize. The Journal of Heredity, 18(6):266-270, 1927.

BURNHAM, C.R. Chromosome segregation in chain-forming translocation in maize. Genetics, 35:99-100, 1950a.

Chromosome segregation in translocation involving chromosome 6 in maize. Genetics, 35:446481, $1950 \mathrm{~b}$.

Chromosomal interchange in plants. The Botanical Review, 22(7): 419-552, 1956. $375 \mathrm{p}$.

LONGLEY, A.E. Chromosome morphology in maize and its relatives. The Botanical Review, 7(4):263-289, 1941.

MAGUIRE, M.P. Direct cytological evidence for true terminalization of chiasmata in maize. Chromosoma, 71(3):282-287, 1979.

MEDINA, D.M. \& CONAGIN, C.T.M. Técnica citológica. Campinas, Instituto Agronômico, 1964. 110p.

REEVES, R.C. \& MANGELSDORF, P.C. A proposed taxonomic change in tribe Maydeae (family Gramineae). American Journal of Botany, 29:815$817,1942$.

SYBENGA, J. Meiotic configurations. Berlin Heidelberg, Springer Verlag, 1975. $251 \mathrm{p}$.

WILKES, H.C. Hibridization of maize and teosinte in Mexico and Guatemala and the improvement of maize. Economic Botany, 31(3):254-293, 1977.

Maize and its wild relatives. Science, 177:1071-1077, 1972.

Mexico and Central America as a center for the origin of agriculture and the evolution of maize. Crop Improvement, 6(1):1-18, 1979.

Teosinte: the closest relatives of maize. Cambridge, The Bussey Inst. of Harvard Univ., 1967. 159p. Thesis (Ph.D.) 